$\mathbb{T}$ periodica polytechnica

Civil Engineering

$58 / 2(2014) 143-154$

doi: $10.3311 /$ PPci.2201

http://periodicapolytechnica.org/ci

Creative Commons Attribution (1)

RESEARCH ARTICLE

\section{Optimization of resilient modulus prediction from FWD results using artificial neural network}

\author{
Bashar Tarawneh / Munir D. Nazzal
}

Received 2013-07-05, revised 2014-01-19, accepted 2014-03-14

\begin{abstract}
One of the most important steps in the design of new pavements and overlays is the selection of an accurate input value for the subgrade resilient modulus $\left(M_{r}\right)$. This paper evaluates the use of regression analysis and artificial neural networks (ANN) to develop models that can be used to accurately predict the subgrade $M_{r}$ design input value using Falling Weight Deflectometer $(F W D)$ test results. The results of the regression analyses conducted in this paper indicated that the use of linear elastic analysis for backcalculation of the FWD modulus yielded better prediction of laboratory measured resilient modulus compared to using the AASHTO or Florida Equations. In addition, the accuracy of Mr prediction was significantly enhanced when ANN based models were used. For models that were based on FWD modulus backcalculated using different software programs, the ANN improvement was only noticed when the model included soil physical properties. Finally, the results of this paper indicated that when using the FWD modulus backcalculated using the AASHTO or Florida equation to predict $M_{r}$ design input value, it's recommended to use the ANN model with variables selected using stepwise selection analysis.
\end{abstract}

\section{Keywords}

Resilient Modulus · Artificial Neural Networks · Falling Weight Deflectometer

\section{Bashar Tarawneh}

Department of Civil Engineering, The University of Jordan, Amman, 11942, Jordan

e-mail: btarawneh@ju.edu.jo

\section{Munir D. Nazza}

Department of Civil Engineering, Ohio University, Athens, Ohio, USA e-mail: nazzal@ohio.edu

\section{Introduction}

The resilient modulus $\left(M_{r}\right)$ is a property that describes the non-linear stress-strain behavior of various soil materials under repeated traffic loading. Different pavement design procedures, including the AASHTO 1993 guide for design of pavement structures and the mechanistic empirical pavement design guide (MEPGD) [1] have adopted the $M_{r}$ of subgrade soils as the main material input parameter property in characterizing pavements for their structural design. Consequently, different state highway agencies have been focusing their effort on developing approaches to accurately measure and predict the $M_{r}$ to ensure the efficiency and accuracy of their pavement designs.

The $M_{r}$ should be determined by conducting repeated load triaxial (RTL) laboratory tests. However, this test requires welltrained personnel and expensive laboratory equipment. In addition, it is considered to be relatively time consuming. Therefore, $M_{r}$ is estimated using correlations with different in-situ test results as well as material index properties. The accuracy of the estimated resilient modulus depends on the precision of the prediction model.

One of the main non-destructive in-situ devices that are commonly used to estimate the stiffness properties of subgrade soil is the Falling Weigh Deflectomter (FWD). The FWD is a trailermounted device, which delivers an impulse load to the pavement. The equipment automatically lifts a weight to a given height. The weight is dropped onto a $300 \mathrm{~mm}$ circular load plate with a thin rubber pad mounted underneath. A load cell measures the force or load applied to the pavement under the plate. While the deflections caused by the impulse load are measured by sensors placed at different distance from the center of load plate. Based on the measured load and deflections, the elastic moduli of the tested pavement layers can be backcalculated using one of the different software programs available, such as MODULUS, ELMOD and EVERCALC software.

Few models were developed in the past decade to estimate laboratory measured $M_{r}$ from FWD backcalculated modulus. The AASHTO recommends equation (Eq. (1p) to compute the FWD backcalculated modulus used to predict the resilient modulus. Furthermore, the AASHTO suggests multiplying the FWD 
backcalculated modulus by an adjustment factor not exceeding 0.33 to determine the $M_{r}$ value used for the design of overlays. Choubane and McNamara [2] suggested that the pavement deflections measured 36 inches away from the load are appropriate for the determination of the subgrade moduli. Based on 300 field FWD tests conducted within the state of Florida, Choubane and McNamara (2000) proposed equation (Eq. (2)) to backcalculate the FWD moduli used to estimate the resilient modulus of subgrade soils. It is noted that this equation will be referred to as the Florida equation in this paper.

$$
\begin{gathered}
E_{F W D}=\left(\frac{0.24 P}{d_{r} r}\right) \\
E_{F W D}=0.03764\left(\frac{P}{d_{36}}\right)^{0.898}
\end{gathered}
$$

Where:

$E_{F W D}$ FWD backcalculated subgrade modulus (psi)

$P \quad$ Applied load (lb)

$d_{r} \quad$ Pavement deflection at radial distance $\mathrm{r}$ (inch)

$d_{36} \quad$ Deflection measured at radial distance of 36 inches

Malla and Joshi [3] also conducted a study to correlate the laboratory measured $M_{r}$ values and the FWD backcalculated modulus based on the LTPP database. The FWD modulus was backcalculated using MODCOMP 4.2 software. Researchers noted that the backcalculated modulus values were higher than the laboratory resilient modulus values conducted at the same test site. However, no definite relationship exists between the two values, which were attributed to the difference in years of FWD testing and laboratory specimen sampling and testing.

Due to the limitation of the regression analyses, there has been a growing interest during the past decade in the use of new class of computational intelligence systems, known as artificial neural networks (ANN), in pavement design and geotechnical field. An example of that is the adoption and successful use of ANN modeling techniques in the MEPDG (NCHRP 2004). In recent years, ANN algorithms have also gained recognition for rapid and accurate predictions of some of the pavement layer parameters. Brendenhann and van de Ven [4] used backpropagation neural networks to estimate elastic moduli of a flexible pavement layer. Ceylan et al. [5-7] developed approaches for predicting HMA dynamic modulus, $\left|E^{*}\right|$, using the ANN methodology based on the input parameters of the Witczak $\left|E^{*}\right|$ model. Bayrak et al. [8] used their ANNs to evaluate the resilient moduli of Iowa flexible pavement materials. Hashash et. al. [9] developed an ANN model which can learn and predict soil stress-strain behaviors from finite element data sets. Kisgyorgy and Rilett [10] used Modular Neural Networks to forecast multiple periods of traffic engineering features, such as speed, occupancy and volume, and then determine the expected travel times based on these predicted values, using currently applied methods.
Tarawneh [11] developed ANN model to predicted pipe pile setup, from field data, and discussed the choice of inputs and internal network parameters to obtain the optimum ANN model. The developed ANN model satisfactory predicted pipe pile setup and significantly outperformed some examined empirical formulas.

Tarawneh and Imam [12] developed ANN and multiple linear regression models to predicted pile setup for three pile types (pipe, concrete, and H-pile) using 169 dynamic load tests. It was concluded that the ANN model outperforms both the multiple linear regression model and the examined empirical formulae in predicting the measured pile setup. Static load test data was also used to further verify the developed models.

This paper evaluates the use of artificial neural network to improve the accuracy of the prediction of subgrade $M_{r}$ from FWD test results.

\section{Data collection and analysis}

The results of $M_{r}$ tests that were conducted on various types of subgrade soils from different pavement sections within the Louisiana State were collected from previous studies [13]. The test data were reviewed and evaluated to identify any inconsistencies. Tab. 1 presents the ranges of properties of subgrade soils included in this study. For each of the $M_{r}$ test results collected, the average value of the resilient modulus for the last ten cycles of each stress sequence was first calculated; the $M_{r}$ data of each test were fit to the generalized $M_{r}$ constitutive model shown in Eq. (3) to determine the $k_{1-3}$ coefficients. The obtained parameters were then used to compute the resilient modulus at a deviator stress of $6 \mathrm{psi}$ and a confining pressure of $2 \mathrm{psi}$, which is an estimate of the state of stress encountered in the subgrade layer under traffic loading that was reported in previous studies (NCHRP 2004). The computed value was used as the field representative values of $M_{r}$.

$$
\frac{M_{r}}{P_{a}}=k_{1}\left(\frac{\theta}{P_{a}}\right)^{k_{2}}\left(\frac{\tau_{o c t}}{P_{a}}+1\right)^{k_{3}}
$$

where $M_{r}$ is the resilient modulus, $\theta$ is the bulk stress, $\tau_{o c t}$ is octahedral shear stress, $P_{a}$ is a normalizing stress equals to atmospheric stress $\left(P_{a}=101.4 \mathrm{kPa}\right)$, and $k_{1}, k_{2}, k_{3}$ are coefficients of the tested material.

\section{Development of regression models to predict re- silient modulus}

A comprehensive statistical analysis was conducted to develop regression models that better predict the resilient modulus of subgrade soils from their index properties. A stepwise linear regression analysis was initially performed to identify the important independent variables (physical properties) that affect the prediction of the resilient modulus.

A Stepwise Iteration (SI) procedure was used where the termination of the independent variables elimination process is 
Tab. 1. Summary of Variables Investigated in this Study

\begin{tabular}{|c|c|c|c|c|}
\hline Property & Range of A-4 soils & $\begin{array}{c}\text { Range for A-6 } \\
\text { soils }\end{array}$ & $\begin{array}{l}\text { Range for A-7-5 } \\
\text { soils }\end{array}$ & $\begin{array}{c}\text { Range for A-7-6 } \\
\text { soils }\end{array}$ \\
\hline Lab. $M_{r}(\mathrm{ksi})$ & $6-8$ & $2-14$ & $2-14$ & $1-11$ \\
\hline $\mathrm{PI}(\%)$ & $<6$ & $11-23$ & $27-61$ & $15-66$ \\
\hline$\gamma_{d}(\mathrm{pcf})$ & $100-107$ & $94-115$ & $77-103$ & $62-112$ \\
\hline$\gamma_{d \max }(\mathrm{pcf})$ & 101.3 & $105-119$ & $76-115$ & $94.2-107.3$ \\
\hline W (\%) & $21-25$ & $9-29$ & $21-37$ & $18-65$ \\
\hline LL (\%) & 28 & $27-40$ & $46-98$ & $41-93$ \\
\hline Sand (\%) & 7 & $11-35$ & $4-28$ & $2-32$ \\
\hline Silt (\%) & 70 & $30-72$ & $9-62$ & $14-58$ \\
\hline Clay (\%) & 23 & $8-32$ & $27-86$ & $32-84$ \\
\hline $\begin{array}{c}\text { Passing sieve \#200 } \\
(\%)\end{array}$ & 93 & $65-89$ & $72-96$ & $68-98$ \\
\hline
\end{tabular}

based on the t-test and F-test outcomes. The stepwise regression analysis combines the forward and backward stepwise regression methods. It fits all possible simple linear models and chooses the best one with largest F-test statistic value. The significance of each variable included is rechecked at each step along the way and removed if it falls below the significance threshold. The process is completed when no more variables outside the model have the significance level to enter. However, at each stage of the procedure the deletion of early selected independent variables is permitted.

The analysis included the following independent variables and their interactions: $M_{r}$ which is backcalculated from FWD using different methods, liquid limit (LL), plasticity index (PI), $\%$ passing sieve No.200, \% clay, \% silt, optimum moisture content, maximum dry unit weight, in situ moisture content, and in situ dry unit weight.

Based on the results of the stepwise iteration procedure, multiple regression models were developed that predict the $M_{r}$ based on the physical properties of tested soils. Tab. 2 summarizes the results of the linear regression analyses. Eleven (11) models were developed using three backcalculation software packages to interpret the FWD data, namely ELMOD 5.1.69, MODULUS 6.0, and EVERCALC 5.0. In addition, the AASHTO and Florida backcalculation equations were also used for comparison.

The adequacy of the developed models was assessed in this study using the coefficient of determination, $R^{2}$, and the mean standard square error of estimate (MSE). The $R^{2}$ represents the proportion of variation in the dependent variable that is accounted for by the regression model and has values from zero to one. If it is equal to one, the entire observed points lie on the suggested least square line, which means a perfect correlation exists. In addition, the mean standard square error of estimate measures the accuracy in the predicted values.

The results showed that the coefficient of determination, $R^{2}$ values for the developed models were between 0.35 and 0.79 . While the adjusted $R^{2}$ values were between 0.34 and 0.78 . Three models have $R^{2}$ values equal to or more than 0.77 . Five models have $R^{2}$ values between 0.5 and 0.7 . However, three models have $R^{2}$ value less than 0.5 .

The regression outcomes showed that Models 1, 2, and 3 which used ELMOD software as backcalculation software to interpret the FWD have the highest $R^{2}$ and least MSE values. $M_{r E L M O D}, \gamma_{d \max }$, and Clay (\%) were the significant independent variables in the three models. The resulting and adjusted $R^{2}$ values were $0.78,079,0.77$ and $0.77,0.78,0.76$, respectively. The MSE values were $1.35,1.3$, and 1.42 respectively.

Model 5 used the Florida backcalculation equation to interpret the FWD has a resulting and adjusted $R^{2}$ values of 0.53 and 0.52 , respectively and MSE value of $2.87 M_{r}$ Florida $E q$ and $\gamma_{d \max }$ were the significant independent variable in this model.

Model 6 used the AASHTO backcalculation equation to interpret the FWD has a resulting and adjusted $R^{2}$ values were 0.5 and 0.49 , respectively and MSE value of 2.99

$M_{r}$ AAS HTO Eq was the only significant independent variable in this model.

Correlations between the predicted resilient modulus from the regression models and the lab estimated resilient modulus for models 1,2,3,5 and 6 are presented in Fig. 1 through Fig. 5

It is noted that soil properties such as clay content (clay (\%)), the dry density $\left(\gamma_{d}\right)$, and liquid limit LL $(\%)$, was found to be significant independent variables in several models as shown in Tab. 22 This indicates that those properties have considerable impact on the resilient modulus values of tested soils.

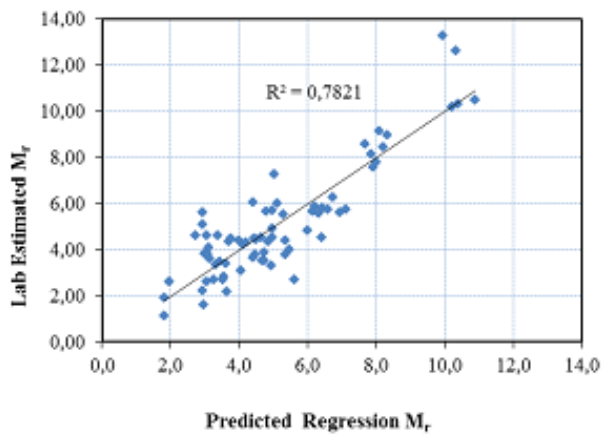

Fig. 1. Lab Estimated $M_{r}$ versus Predicted using Regression Model-1 
Tab. 2. Summary of Developed Regression Models

\begin{tabular}{|c|c|c|c|c|c|c|c|}
\hline \multirow[b]{2}{*}{ Model Variables } & \multicolumn{2}{|c|}{$\begin{array}{l}\text { Un-standardized } \\
\text { Coefficients }\end{array}$} & \multirow[b]{2}{*}{$\begin{array}{c}\text { Standar- } \\
\text { dized } \\
\text { Coeffi- } \\
\text { cient } \\
\mathbf{a}_{n} \\
\end{array}$} & \multirow[b]{2}{*}{$\begin{array}{c}\text { MSE } \\
\text { (mean } \\
\text { square } \\
\text { error) }\end{array}$} & \multirow[b]{2}{*}{$\mathbf{R}^{2}$} & \multirow[b]{2}{*}{$\mathbf{R}_{\text {Ajusted }}^{2}$} & \\
\hline & $\mathbf{a}_{n}$ & $\begin{array}{l}\text { Std. } \\
\text { Error }\end{array}$ & & & & & \\
\hline Model-1 & $\begin{array}{c}\text { Constant } \\
\left(a_{0}\right)\end{array}$ & 11.724 & 2.342 & & \multirow{4}{*}{1.35} & \multirow{4}{*}{0.78} & \multirow{4}{*}{0.77} \\
\hline ELMOD & $M_{r E L M O D}$ & 0.458 & 0.030 & 0.968 & & & \\
\hline (7 Sensors, & $\gamma_{d \max }$ & -0.100 & 0.021 & -0.431 & & & \\
\hline No Seed) & Clay (\%) & -0.040 & 0.011 & -0.308 & & & \\
\hline Model-2 & $\begin{array}{c}\text { Constant } \\
\left(a_{0}\right)\end{array}$ & 12.559 & 2.321 & & \multirow{4}{*}{1.3} & \multirow{4}{*}{0.79} & \multirow{4}{*}{$0.7 \varepsilon$} \\
\hline ELMOD & $M_{r E L M O D}$ & 0.447 & 0.028 & 0.975 & & & \\
\hline (9 Sensors, & $\gamma_{d \max }$ & -0.105 & 0.021 & -0.452 & & & \\
\hline No Seed) & Clay (\%) & -0.045 & 0.011 & -0.348 & & & \\
\hline Model-3 & $\begin{array}{c}\text { Constant } \\
\left(a_{0}\right)\end{array}$ & 12.454 & 2.417 & & \multirow{4}{*}{1.42} & \multirow{4}{*}{0.77} & \multirow{4}{*}{0.76} \\
\hline ELMOD & $M_{r E L M O D}$ & 0.448 & 0.030 & 0.965 & & & \\
\hline (9 Sensors, & $\gamma_{d \max }$ & -0.105 & 0.021 & -0.449 & & & \\
\hline Seed) & Clay (\%) & -0.045 & 0.011 & -0.348 & & & \\
\hline Model-4 & $\begin{array}{c}\text { Constant } \\
\left(a_{0}\right)\end{array}$ & 5.325 & 1.979 & & \multirow{3}{*}{2.8} & \multirow{3}{*}{0.54} & \multirow{3}{*}{0.53} \\
\hline EVER- & $M_{r E V E R C A L C}$ & C 0.318 & 0.036 & 0.809 & & & \\
\hline CALC 5.0 & $\gamma_{d \max }$ & -0.049 & 0.021 & -0.209 & & & \\
\hline Model-5 & $\begin{array}{c}\text { Constant } \\
\left(a_{0}\right)\end{array}$ & 4.495 & 1.984 & & \multirow{3}{*}{2.87} & \multirow{3}{*}{0.53} & \multirow{3}{*}{0.5} \\
\hline Florida & $M_{r}$ Florida $E q$ & 0.296 & 0.034 & 0.790 & & & \\
\hline Equation & $\gamma_{\operatorname{dmax}}$ & -0.043 & 0.021 & -0.184 & & & \\
\hline Model-6 AASHTO & $\begin{array}{c}\text { Constant } \\
\left(a_{0}\right)\end{array}$ & 1.120 & 0.514 & & \multirow[t]{2}{*}{2.99} & \multirow[t]{2}{*}{0.5} & \multirow[t]{2}{*}{0.49} \\
\hline Equation & $M_{r}$ AASHTO E & $E q 0.303$ & 0.036 & 0.708 & & & \\
\hline Model-7 & $\begin{array}{c}\text { Constant } \\
\left(a_{0}\right)\end{array}$ & 10.703 & 2.900 & & \multirow{4}{*}{2.07} & \multirow{4}{*}{0.67} & \multirow{4}{*}{0.65} \\
\hline MODULUS 6.0 & Mr Modulus 6 & 0.458 & 0.040 & 0.888 & & & \\
\hline Cal = 2 & $\gamma_{d \max }$ & -0.086 & 0.026 & -0.368 & & & \\
\hline (9 Sensors) & Clay $(\%)$ & -0.033 & 0.13 & -0.253 & & & \\
\hline Model-8 MODULUS 6.0 & $\begin{array}{c}\text { Constant } \\
\left(a_{0}\right)\end{array}$ & 0.525 & 0.562 & & 2.89 & \multirow[t]{2}{*}{0.52} & 0.51 \\
\hline Semi Inf. (7 Sensors) & $M_{r \text { Modulus } 6}$ & 0.292 & 0.033 & 0.720 & & & \\
\hline Model-9 MODULUS 6.0 & $\begin{array}{c}\text { Constant } \\
\left(a_{0}\right)\end{array}$ & 1.308 & 0.664 & & 3.92 & 0.35 & 0.34 \\
\hline E4 = 100 (7 Sensors) & $M_{r \text { Modulus } 6}$ & 0.376 & 0.061 & 0.588 & & & \\
\hline Model-10 MODULUS 6.0 & $\begin{array}{c}\text { Constant } \\
\left(a_{0}\right)\end{array}$ & 0.852 & 0.643 & & 3.53 & 0.41 & 0.4 \\
\hline E4 = 5 (7 Sensors) & $M_{r \text { Modulus } 6}$ & 0.372 & 0.053 & 0.642 & & & \\
\hline Model-11 MODULUS 6.0 & $\begin{array}{c}\text { Constant } \\
\left(a_{0}\right)\end{array}$ & 0.739 & 0.632 & & 3.4 & 0.43 & 0.42 \\
\hline E4 = 3 (7 Sensors) & $M_{r \text { Modulus } 6}$ & 0.355 & 0.048 & 0.658 & & & \\
\hline
\end{tabular}




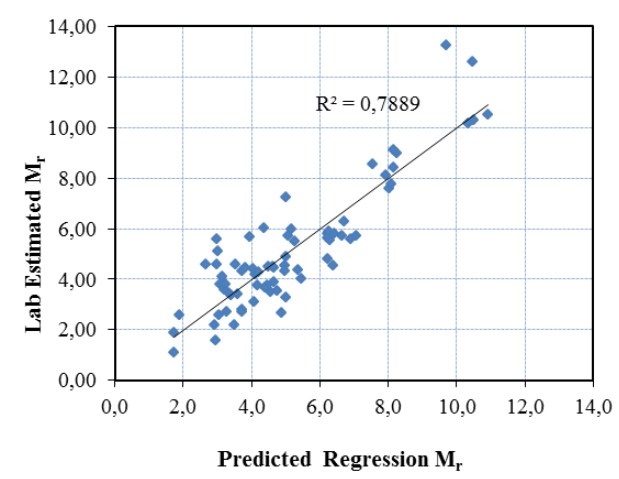

Fig. 2. Lab Estimated $M_{r}$ versus Predicted using Regression Model-2

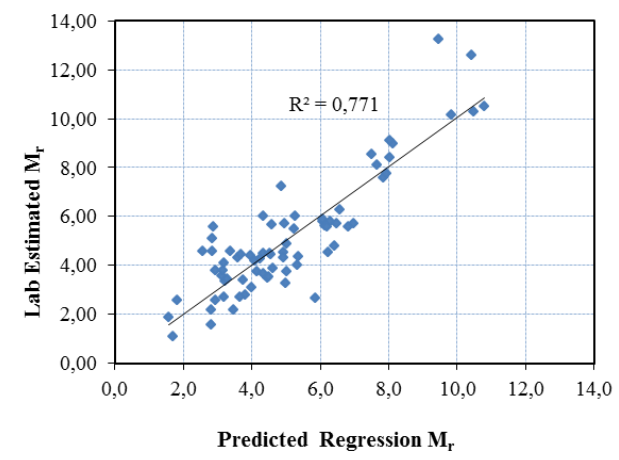

Fig. 3. Lab Estimated $M_{r}$ versus Predicted using Regression Model-3

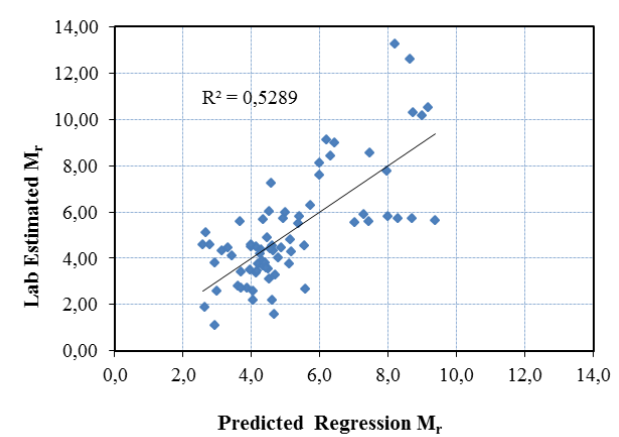

Fig. 4. Lab Estimated $M_{r}$ versus Predicted using Regression Model-5 (Florida Equation)

\section{Artificial neural network}

Over the past two decades, artificial neural networks (ANN) have emerged as powerful and versatile computational tools for organizing and correlating information in ways that have proved useful for solving certain types of problems that are difficult to tackle using traditional numerical and statistical methods [14].

ANNs consists of a group of artificial neurons that are interconnected in a way similar to the architecture of the human brain. This computational technique has the ability to recognize, capture and map features known as patterns contained in a set of data mainly due to the high interconnections of neurons that process information in parallel [14]. A network that has learned the patterns defining the relationship between the input

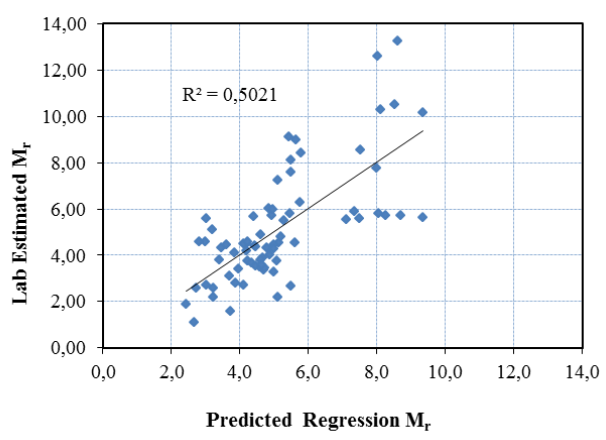

Fig. 5. Lab Estimated $M_{r}$ versus Predicted using Regression Model-6 (AASHTO Equation)

and output of a certain test or process can later be used to predict new conditions for which the output are not known. An ANN system consists of three or more layers. The first layer has the input neurons (parameters) while the last layer contains the output. In addition, one or more layers can be between the input and output layers, which are known as the hidden layers. Those layers form the network's means of delineating and learning the patterns governing the data that the network is presented with.

There are many ways a neural network can be trained. The backpropagation technique, which was developed by Rumelhart et. al [15], is the most popular process and has been used in many fields of science and engineering. With this method, the weights of the network are adjusted during the training phase to minimize the error. In each iteration, the error propagates backward to minimize the error to a desired level.

\subsection{Development of artificial neural networks models to predict resilient modulus}

Backpropagation neural network algorithms were adopted in this study to develop ANN models that can accurately predict the resilient modulus. $70 \%$ of the data points were selected randomly for training, $15 \%$ were selected for cross validation, and $15 \%$ were used for testing the network. The training data points were used to train the network and compute the weights of the inputs. The test data points were used to measure the performance of the selected ANN model. The cross validation computes the error in a test set at the same time that the network is being trained with the training set. Several network structures with different number of nodes in the hidden layer were trained and tested. This strategy was chosen to find the best performing network architecture among different models.

Neuro-Solutions 6.0 software was used in creating the neural network models. This software combines a modular design interface with advanced learning procedures, giving the power and flexibility needed to design the neural network that produces the best solution. Multilayer perceptron (MLP) with one hidden layer and hyperbolic tangent (tanh) as a transfer function was used in creating the neural networks. The hidden layer has four processing elements. The (tanh) transfer function was used 
for both the hidden and the output layers. Levenberg rule was selected as the training rule. Based on running several neural network models using Neuro-Solutions 6.0 software, the best performing neural network models were chosen.

Two approaches were used to develop ANN models to predict the resilient modulus:

1 ANN models were developed using all independent variables, namely: $M_{r}$ which is backcalculated from FWD using different methods, liquid limit (LL), plasticity index (PI), \% passing sieve No.200, \% clay, \% silt, optimum moisture content, maximum dry unit weight, in situ moisture content, and in situ dry unit weight. All these variables were used as model predictors for $M_{r}$. A total of twelve ANN models were developed. These models were called all variables models (AVM)

2 ANN models were developed using the same variables that were used in the aforementioned regression models presented in Tab. 2. These variables were selected in the development of ANN models for predicting $M_{r}$. A total of twelve ANN models were developed. These models were called selected variables models (SVM). This approach was used to compare the regression result to the ANNs results.

The proceeding sections provide a description of results of analyses conducted using each of those approaches.

\subsubsection{All variables models (AVM):}

All variables listed in Tab. 1 were used as model predictors (independent variables) except the lab $M_{r}$ which was used as a model desired (dependant variable). Tab. 3 shows a summary of the results for the developed ANN models. The table provides the mean square error (MSE) for the training, cross validation and testing data. It also provides the $R^{2}$ for the testing data.

As shown in Fig. 6, the chosen neural network model consisted of an input layer with 10 input variables, one hidden layer with 4 neurons, and an output layer with 1 output variable prediction.

The results showed that the coefficient of determination, $R^{2}$ values for the developed AVM were between 0.23 and 0.87 . Two models have $R^{2}$ values equal to higher than 0.85 . Five models have $R^{2}$ values between 0.6 and 0.78 . However, four models have $R^{2}$ value less than 0.5 .

The ANNs for the AVM outcomes showed that Models 1, 2, and 3 which used ELMOD software for the backcalculation of the FWD modulus, had the highest $R^{2}$ values and lowest MSE values. Furthermore, the best model was Model 3 that used the FWD modulus backcalculated using ELMOD software using 9 sensors with seed values.

Models 7, 9, and 11 had the lowest $R^{2}$ values and highest MSE values; thus those models have the least accuracy in the prediction of the $M_{r}$ design values. It is noted that in those models, the FWD modulus backcalculated using MODULUS 6.0 software was used. Furthermore, the regression analysis had showed similar results. The results in Tab. 3 also indicate that the prediction of $M_{r}$ using the ANN model that was based on using AASHTO backcalculation equation was significantly enhanced and the $R^{2}$ increased to 0.6

Fig. 7 thru Fig. 9 illustrate correlations between desired output (lab estimated resilient modulus) and networks predicted output for AVM 3, 6 and 1 respectively. Each figure shows training, cross validation, and testing data.

\subsubsection{Selected variables models (SVM)}

ANN models were developed using the same variables that were used in the aforementioned regression models presented in Tab. 2. These variables were selected in the development of ANN models for predicting $M_{r}$. A total of eleven ANN models were developed. These models were called selected variables models (SVM). This approach was used to compare the regression result to the ANNs results. Fig. 10 presents typical structure of neural network selected variables models (SVM). As shown in figure, the chosen neural network model consisted of an input layer with 3 input variables, one hidden layer with 4 neurons, and an output layer with 1 output variable prediction.

Tab. 4 presents a summary of the results for the developed ANN models. The table provides the MSE for the training, cross validation and testing data. It also provides the $R^{2}$ for the testing data.

When comparing to regression models, it's clear that the highest improvement is shown in model 5. In this model, the network inputs were $M_{r}$ Florida Equation and $\gamma_{d \max }$, The ANNs increased the adjusted $R^{2}$ from 0.52 to 0.72 and reduced the MSE from 2.87 to 1.51 for the testing data. While in model 4, network inputs were $M_{r \text { Evercalc }}$ and $\gamma_{\text {dmax }}$, ANNs enhanced the adjusted $R^{2}$ value by 0.12 (from 0. 54 to 0.66 ). In model $6, M_{r}$ AAS HTO was the only input for the network; ANNs improved the adjusted $R^{2}$ value by 0.13 (from 0. 49 to 0.62 ) for this model.

$M_{r \text { ELMOD }}, \gamma_{\text {dmax }}$, Clay (\%) were the network inputs for models 1,2 and 3. ANNs enhanced the adjusted $R^{2}$ by 0.04 (from 0.77 to 0.81 ) for model 1 , by 0.11 (from 0.78 to 0.89 ) for model 2 , and by 0.1 (from 0.76 to 0.86 ) for model 3 .

AANs enhanced the adjusted $R^{2}$ value by 0.05 for model 1 (from 0.4 to 0.45 ). ANNs didn't enhance the adjusted $R^{2}$ values for Models 8, 9, and 11 for those models the $R^{2}$ values resulting from ANNs were less than the one resulting from regression.

Generally, ANNs improved eight of the eleven regression models by increasing the $R^{2}$ values and reducing the mean square error (MSE). The analysis showed that when the network has only one input there will be no improvement to the adjusted $R^{2}$ value and regression model is recommended to be used. However, the only exceptional case was model 6 which used the $M_{\text {r AAS HTO }}$ as the only input to the network.

Fig. 11 and Fig. 12 illustrate correlations between desired output (lab estimated resilient modulus) and networks predicted output for SVM 2 and 6 respectively. Each figure shows training, cross validation, and testing data. $R^{2}$ value and a linear regression line are provided for the testing data. 


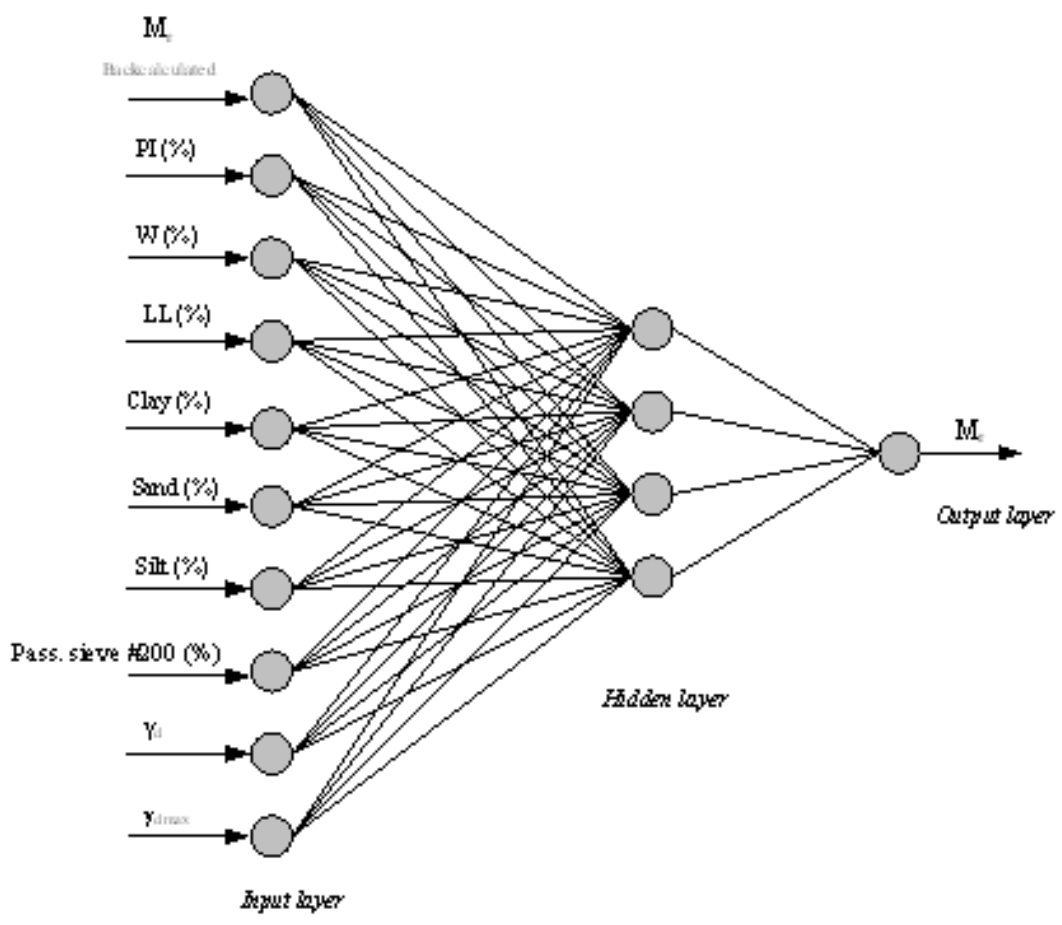

Fig. 6. Three-Layer Neural Network Representing AVM

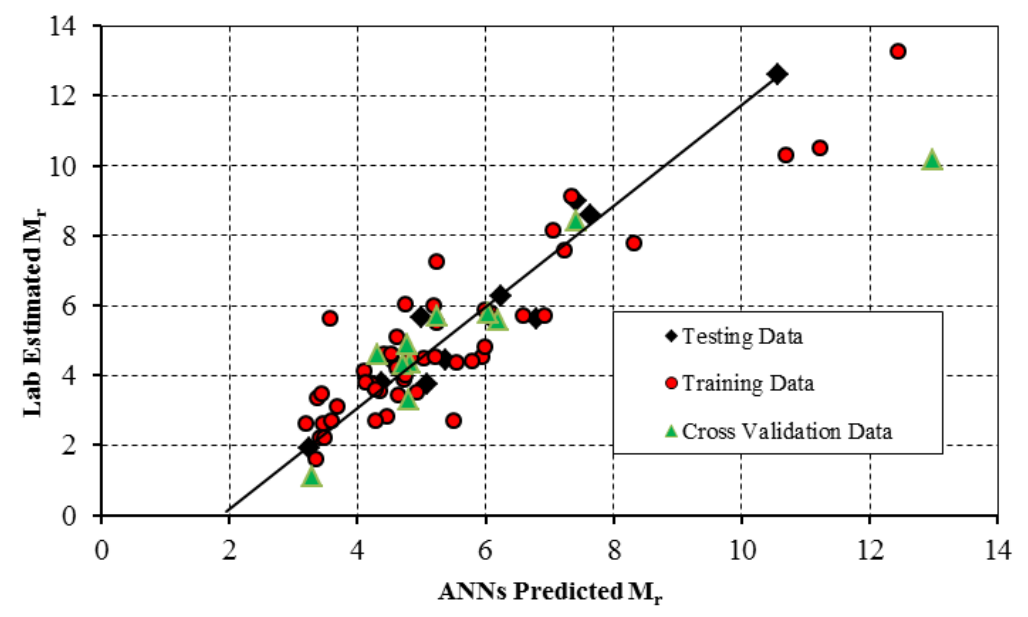

Fig. 7. Lab Estimated $M_{r}$ versus Predicted using ANN AVM-3

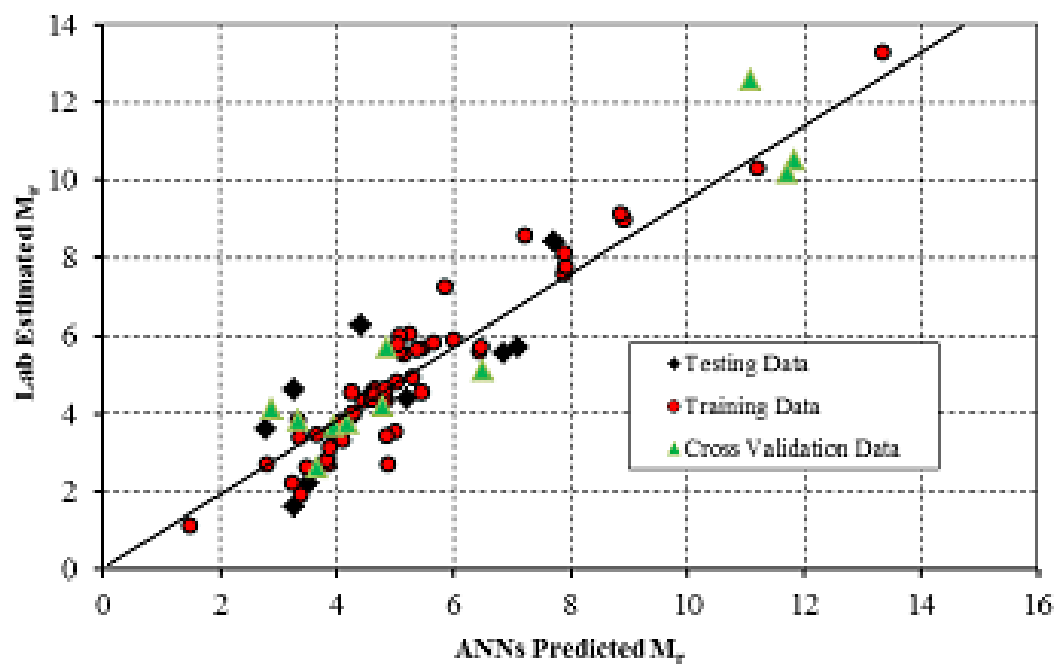

Fig. 8. Lab Estimated $M_{r}$ versus Predicted using ANN AVM-6 (AASHTO Equation) 
Tab. 3. Summary of ANN for All Variables Models (AVM)

\begin{tabular}{|c|c|c|c|c|c|}
\hline \multirow{2}{*}{ AVM Model } & \multirow{2}{*}{ Network Inputs } & \multirow{2}{*}{$\begin{array}{c}\text { Training } \\
\text { MSE }\end{array}$} & \multirow{2}{*}{$\begin{array}{c}\text { Cross } \\
\text { Validation }\end{array}$} & \multicolumn{2}{|c|}{ Testing } \\
\hline & & & & MSE & $R^{2}$ \\
\hline 1 & $\begin{array}{c}M_{r} \text { ELMOD, (7 } \\
\text { Sensors, No } \\
\text { Seed) and all } \\
\text { independent } \\
\text { variables* }\end{array}$ & 0.002 & 0.008 & 1.088 & 0.87 \\
\hline 2 & $\begin{array}{c}M_{r E L M O D},(9 \\
\text { Sensors, No } \\
\text { Seed) and all } \\
\text { independent } \\
\text { variables* }^{*}\end{array}$ & 0.0015 & 1.386 & 4.122 & 0.78 \\
\hline 3 & $\begin{array}{c}M_{r} \text { ELMOD, }(9 \\
\text { Sensors, Seed) } \\
\text { and all } \\
\text { independent } \\
\text { variables }^{*}\end{array}$ & 0.00007 & 0.039 & 1.88 & 0.85 \\
\hline 4 & $\begin{array}{c}M_{r \text { EVERCALC }} \\
\text { and all } \\
\text { independent } \\
\text { variables }^{*}\end{array}$ & 0.0029 & 0.046 & 1.636 & 0.62 \\
\hline 5 & $\begin{array}{c}M_{r} \text { Florida Eq. } \\
\text { and all } \\
\text { independent } \\
\text { variables* }\end{array}$ & 0.0024 & 1.0198 & 4.417 & 0.41 \\
\hline 6 & $\begin{array}{c}M_{r \text { AAS HTO Eq. }} \\
\text { and all } \\
\text { independent } \\
\text { variables* }\end{array}$ & 0.0007 & 0.0614 & 1.386 & 0.6 \\
\hline 7 & $\begin{array}{c}M_{r \text { Modulus }} \\
\text { (Cal =2, } 9 \\
\text { Sensors) and } \\
\text { all independent } \\
\text { variables }\end{array}$ & 0.0005 & 0.0832 & 3.082 & 0.26 \\
\hline 8 & $\begin{array}{c}\text { Mr Modulus, } \\
\text { (Semi Inf. } 7 \\
\text { Sensors) and } \\
\text { all independent } \\
\text { variables* }\end{array}$ & 0.003 & 0.146 & 1.356 & 0.7 \\
\hline 9 & $\begin{array}{c}M_{r \text { Modulus }} \\
\text { (E4=100, } 7 \\
\text { Sensors) and } \\
\text { all independent } \\
\text { variables* }\end{array}$ & 0.0008 & 0.205 & 2.47 & 0.24 \\
\hline 10 & $\begin{array}{c}M_{r \text { Modulus }} \\
\text { (E4=5 } 7 \\
\text { Sensors) and } \\
\text { all independent } \\
\text { variables* }\end{array}$ & 0.0018 & 0.272 & 1.757 & 0.72 \\
\hline 11 & $\begin{array}{c}M_{r \text { Modulus }} \\
\text { (E4=3,7 } \\
\text { Sensors) and } \\
\text { all independent } \\
\text { variables }^{*}\end{array}$ & 0.0025 & 0.0031 & 11.442 & 0.23 \\
\hline
\end{tabular}

* All variables listed in Tab. 1 except Lab $M_{r}$ 


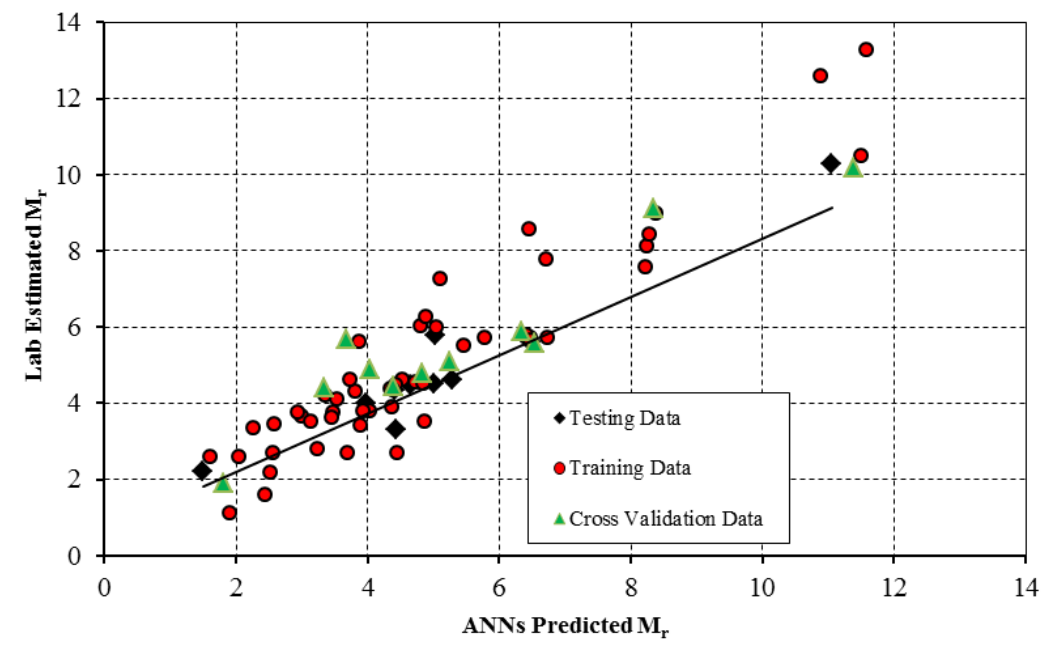

Fig. 9. Lab Estimated $M_{r}$ versus Predicted using ANN AVM-10

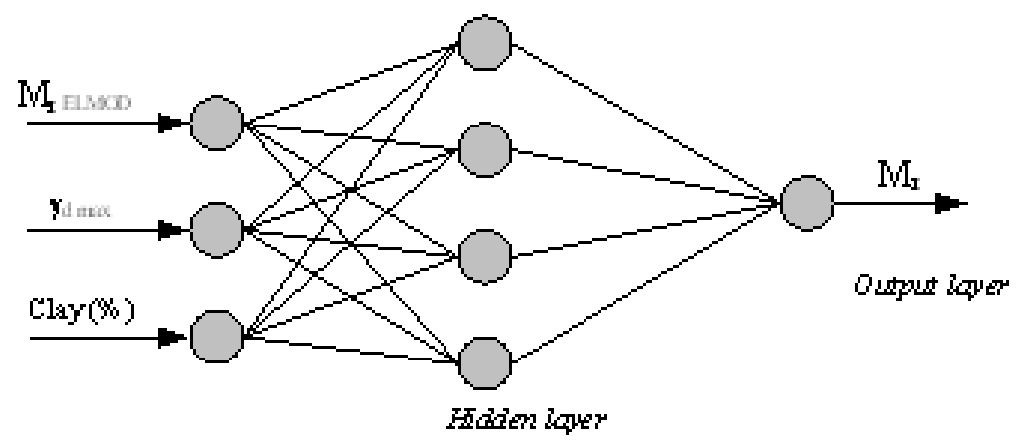

Fig. 10. Three-Layer Neural Network Representing SVM 1, 2 and 3

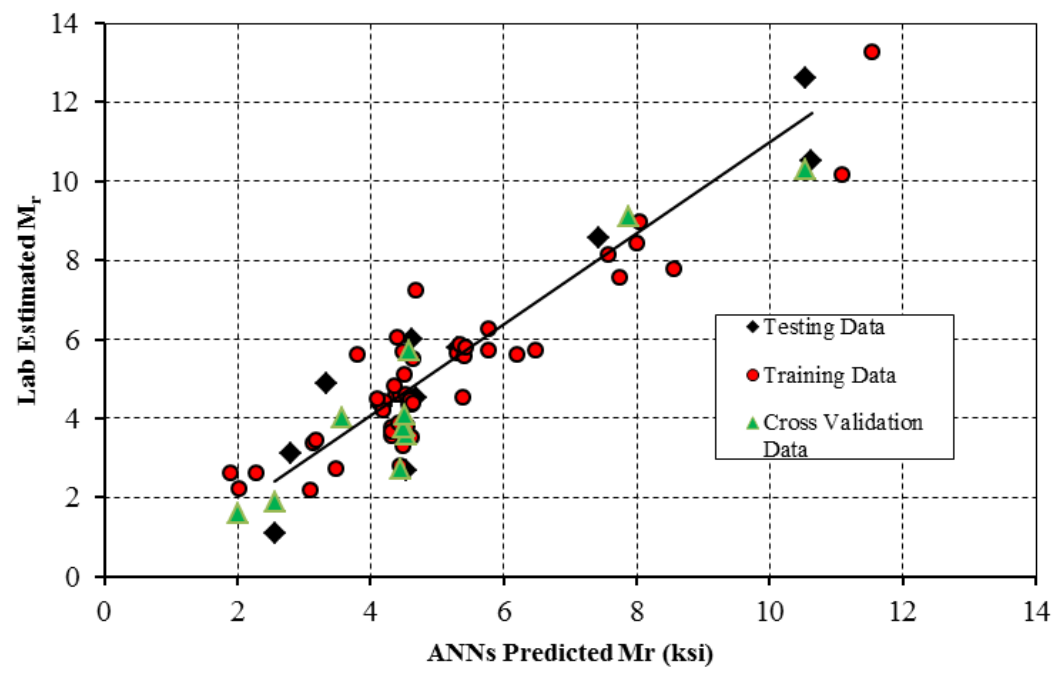

Fig. 11. Lab Estimated $M_{r}$ versus Predicted using ANN SVM-2 
Tab. 4. Summary of ANN for Selected Variables Models (SVM)

\begin{tabular}{|c|c|c|c|c|c|}
\hline \multirow[t]{2}{*}{ ANN Model } & \multirow[t]{2}{*}{ Network Inputs } & \multirow{2}{*}{$\begin{array}{c}\text { Training } \\
\text { MSE }\end{array}$} & \multirow{2}{*}{$\begin{array}{c}\begin{array}{c}\text { Cross } \\
\text { Validation }\end{array} \\
\text { MSE }\end{array}$} & \multicolumn{2}{|c|}{ Testing } \\
\hline & & & & MSE & $R^{2}$ \\
\hline 1 & $\begin{array}{l}M_{r E L M O D}(7 \\
\text { Sensors, No } \\
\text { seed }), \gamma_{d \max }, \\
\text { Clay }(\%)\end{array}$ & 0.0078 & 0.0092 & 0.9175 & 0.81 \\
\hline 2 & $\begin{array}{c}M_{r \text { ELMOD }}(9 \\
\text { Sensors, No } \\
\text { seed }), \gamma_{d \max }, \\
\text { Clay (\%) }\end{array}$ & 0.0064 & 0.0105 & 1.4405 & 0.89 \\
\hline 3 & $\begin{array}{l}M_{r} \text { ELMOD }(9 \\
\text { Sensors, } \\
\text { Seed }), \gamma_{d \text { max }}, \\
\text { Clay }(\%)\end{array}$ & 0.0069 & 0.0127 & 1.1672 & 0.86 \\
\hline 4 & $\begin{array}{c}M_{r \text { EVERCALC }} \\
\gamma_{d \max }\end{array}$ & 0.0076 & 0.0102 & 3.5024 & 0.66 \\
\hline 5 & $\begin{array}{c}M_{r} \text { Florida Eq. } \\
\quad \gamma_{d \max }\end{array}$ & 0.0067 & 0.0205 & 1.5095 & 0.72 \\
\hline 6 & $M_{r \text { AASHTO Eq. }}$ & 0.0296 & 0.0251 & 4.2689 & 0.62 \\
\hline 7 & $\begin{array}{c}M_{r} \text { Modulus } \\
\text { (Cal=2, } 9 \\
\text { Sensors), } \\
\gamma_{d \text { max }} \text { Clay (\%) }\end{array}$ & 0.005 & 0.113 & 1.7257 & 0.68 \\
\hline 8 & $\begin{array}{c}M_{r} \text { Modulus } \\
\text { (Semi Inf.,7 } \\
\text { Sensors) }\end{array}$ & 0.0219 & 0.0159 & 4.9900 & 0.47 \\
\hline 9 & $\begin{array}{c}M_{r} \text { Modulus } \\
\text { (E4=100, } 7 \\
\text { Sensors) }\end{array}$ & 0.0223 & 0.0593 & 3.9878 & 0.29 \\
\hline 10 & $\begin{array}{c}M_{r \text { Modulus }} \\
\text { (E4=5, } 7 \\
\text { Sensors) }\end{array}$ & 0.0262 & 0.0955 & 4.2499 & 0.45 \\
\hline 11 & $\begin{array}{c}M_{r \text { Modulus }} \\
\text { (E4=3, } 7 \\
\text { Sensors) }\end{array}$ & 0.0252 & 0.0111 & 4.2640 & 0.26 \\
\hline
\end{tabular}

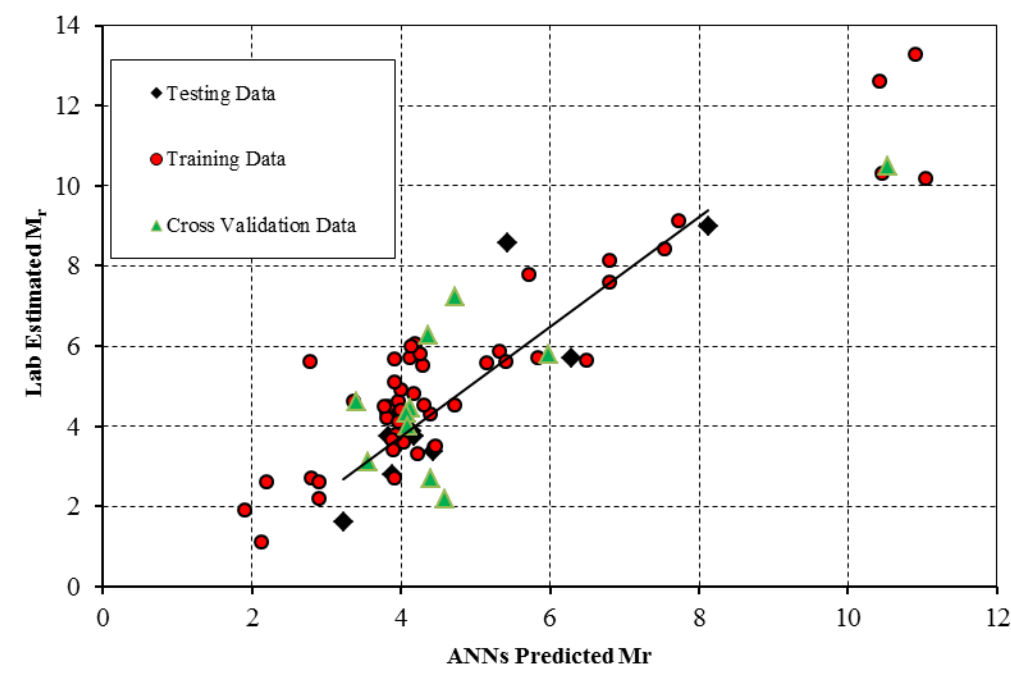

Fig. 12. Lab Estimated $M_{r}$ versus Predicted using ANN SVM-6 (Florida Equation) 


\subsection{Mathematical expression of one of the developed ANN} models

In this section, selected variables model 3 is used as an example to show the mathematical expression of the developed ANNs models. This model consisted of an input layer with three input variables $\left(M_{r E L M O D}\left(9\right.\right.$ Sensors, Seed), $\gamma_{d \max }$, and Clay $\left.(\%)\right)$, one hidden layer with four neurons, and an output layer with one output variable prediction (lab estimated $M_{r}$ ) as shown in Fig. 10. Tab. 5, Tab. 6. Tab. 7 and Tab. 8 provide the numerical values of the ANN amplitude, offset, weights and biases. Detailed procedure on ANN calculation procedure can be found in AlTarawneh 2005 [16].

Tab. 5. Amplitude and Offset for the Input Layer

\begin{tabular}{cc}
\hline Number of Nodes & $\mathbf{3}$ \\
\hline Amplitude $\mathbf{a}_{\text {in }}$ & Offset $\mathbf{O f}_{\text {in }}$ \\
\hline 0.81 & -1.219 \\
\hline 0.023 & -1.085 \\
\hline 0.042 & -4.081 \\
\hline
\end{tabular}

Tab. 6. Weight of Inputs to Hidden Layer $\left(w i_{n m}\right) *$ and Bias of hidden node $\left(b h_{1}, b h_{2}, b h_{3}\right.$, and $\left.b h_{4}\right)$

\begin{tabular}{|c|c|c|c|c|c|c|c|}
\hline 111 & 2.076 & $v_{\text {i21 }}$ & 2.125 & $w_{i 33}$ & 0.090 & $b_{1}$ & 0.249 \\
\hline & -0.896 & $V_{i 2}$ & -1.444 & & 0.997 & & 0.088 \\
\hline & 1.561 & & 1.977 & & -0.238 & & .148 \\
\hline & -1.245 & $w_{\mathrm{i} 24}$ & -1.413 & $w_{i 3}$ & 0.034 & bh & 0.033 \\
\hline
\end{tabular}

$w i_{n m}$ represents the weight from input $n$ to hidden node $m$

Tab. 7. Weights of Hidden layer to Output Layer $\left(w_{o}\right)$ and Bias of Output node $(b o)$

\begin{tabular}{lc}
\hline$w_{o 1}$ & 3.435 \\
\hline$w_{o 2}$ & -2.203 \\
\hline$w_{o 3}$ & -5.088 \\
\hline$w_{o 4}$ & 1.04 \\
\hline$b_{o}$ & 0.13 \\
\hline
\end{tabular}

\subsection{Comparison between Regression and ANNs models}

Tab. 9 provides comparison between $R^{2}$ values for the ANNs models, both AVM and SVM, and the regression models. It is noted that, in general, the use of ANN significantly improved the accuracy of prediction as indicated by the higher $R^{2}$ value

It's clear that model 1, 2, and 3 which used ELMOD software as backcalculation software

to interpret the FWD have the highest $R^{2}$ values when using either linear regression or ANNs. In five models $(2,4,5,6$, and 7) $R^{2}$ values for ANNs SVM were higher than the ones for the ANNs AVM and the linear regression models. ANNs AVM have the highest $R^{2}$ values for models (1, 3, 8, and 1). The linear regression models have the highest $R^{2}$ values for model 9 and 11.
Tab. 8. Amplitude and Offset for the Output Layer

\begin{tabular}{cc}
\hline Number of Nodes & $\mathbf{1}$ \\
\hline Amplitude $\mathbf{a}_{\mathbf{o}}$ & Offset $\mathbf{O f}_{\mathbf{0}}$ \\
\hline 0.148 & -1.063 \\
\hline
\end{tabular}

\section{Conclusions}

This paper presented the results of a study that was conducted to evaluate the use of regression analysis and ANN to develop models that can accurately predict the subgrade $M_{r}$ input value. Based on the results of this study, the following conclusions can be drawn:

- Soil properties such as clay $(\%), \gamma_{d \max }, \mathrm{LL}(\%)$, and $\gamma_{d}$ appeared as significant independent variables (model predictors) to predict $M_{r}$ in several models as shown in Tab. 2 .

- The regression analyses results showed that the use of a linear elastic software for backcalculation of the FWD modulus yielded better prediction of laboratory measured resilient modulus compared to using the AASHTO or Florida Equations. In addition, the models that used FWD modulus backcalculated using ELMOD 5.1.69 had the highest $R^{2}$.

- The use of ANNs significantly enhanced accuracy in model prediction. For FWD backcalculated using linear elastic software programs, the ANN improvement was noticed only when the network has more than one input.

- When using the FWD modulus backcalculated using Florida equation, it's recommended to use the ANNs SVM model. In this model, the network inputs were $M_{r}$ Florida Equation and $\gamma_{d \max }$,

- When using the AASHTO backcalculation equation to interpret the FWD, it's recommended to use the developed ANN model 6. 
Tab. 9. Comparison between Linear Regression and ANNs Models

\begin{tabular}{|c|c|c|c|c|}
\hline \multirow{3}{*}{ Model } & \multirow{3}{*}{$\begin{array}{c}\mathbf{M}_{r} \text { Back- } \\
\text { Calculation } \\
\text { Method }\end{array}$} & \multirow{2}{*}{$\begin{array}{c}\text { Linear Regression } \\
\text { Models }\end{array}$} & \multicolumn{2}{|c|}{ ANNs } \\
\hline & & & SVM $^{*}$ & AVM $^{\star \star}$ \\
\hline & & $\mathbf{R}^{2}$ Adjusted & $\mathbf{R}^{2}$ & $\mathbf{R}^{2}$ \\
\hline 1 & $\begin{array}{l}\text { ELMOD } 5.1 .69 \text { (7 } \\
\text { Sensors, No seed) }\end{array}$ & 0.77 & 0.81 & 0.87 \\
\hline 2 & $\begin{array}{l}\text { ELMOD 5.1.69 (9 } \\
\text { Sensors, No seed) }\end{array}$ & 0.78 & 0.89 & 0.78 \\
\hline 3 & $\begin{array}{c}\text { ELMOD 5.1.69 (9 } \\
\text { Sensors, Seed) }\end{array}$ & 0.76 & 0.86 & 0.85 \\
\hline 4 & EVERCALC 5.0 & 0.54 & 0.66 & 0.62 \\
\hline 5 & Florida Equation & 0.52 & 0.72 & 0.41 \\
\hline 6 & AASHTO Equation & 0.49 & 0.62 & 0.6 \\
\hline 7 & $\begin{array}{c}\text { MODULUS 6.0. } \\
\mathrm{Cal}=2 . \text { (9 Sensors) }\end{array}$ & 0.65 & 0.69 & 0.26 \\
\hline 8 & $\begin{array}{c}\text { MODULUS 6.0. } \\
\text { Semi Inf. (7 } \\
\text { Sensors) }\end{array}$ & 0.51 & 0.47 & 0.7 \\
\hline 9 & $\begin{array}{c}\text { MODULUS } 6.0 . \\
\text { E4 = } 100(7 \\
\text { Sensors })\end{array}$ & 0.34 & 0.29 & 0.24 \\
\hline 10 & $\begin{array}{c}\text { MODULUS } 6.0 . \\
\text { E4 =5 (7 Sensors) }\end{array}$ & 0.4 & 0.45 & 0.72 \\
\hline 11 & $\begin{array}{c}\text { MODULUS 6.0. } \\
\text { E4 =3 (7 Sensors) }\end{array}$ & 0.42 & 0.26 & 0.23 \\
\hline
\end{tabular}

*Selected variables model, ${ }^{* *}$ All variables model

\section{References}

1 National Cooperative Highway Research Program, Guide for mechanistic-empirical design of new and rehabilitated pavement structures, submitted by ARA, Inc., Division), National Research Council, Transportation Research Board, 2008. Final Rep. NCHRP 1-37A (submitted by ARA, Inc., ERES Consultants Division.

2 Choubane B, McNamara RL, A practical approach to predicting flexible pavement embankment moduli using Falling Weight Deflectomter (FWD) data, Florida Department of Transportation, State Materials Office, 2000. Research Report FL/DOT/SMO/00-442.

3 Malla R, Joshi S, Resilient modulus prediction models based on analysis of LTPP data for subgrade soils and experimental verification, Journal of Transportation Engineering, 133(9), (2007), 491-504, DOI 10.1061/(ASCE)0733947X(2007)133:9(491)

4 Bredenhann SJ, van de Ven MFC, Application of artificial neural networks in the back-calculation of flexible pavement layer moduli from deflection measurements, 8th Conference on Asphalt Pavements for Southern Africa (CAPSA '04), In: Proceedings of the 8th Conference on Asphalt Pavements for Southern Africa (CAPSA '04); Sun City, South Africa, 2004.

5 Ceylan H, Kim S, Gopalakrishnan K, Hot mix asphalt dynamic modulus prediction models using neural network approach, ANNIE, In: Proceedings of the ANNIE; New York, USA, 2007.

6 Ceylan H, Gopalakrishnan K, Kim S, Advanced approaches to hot-mix asphalt dynamic modulus prediction, Canadian Journal of Civil Engineering, 35(7), (2008), 699-707, DOI 10.1139/L08-016

7 Ceylan H, Schwartz CW, Kim S, Gopalakrishnan K, Accuracy of Predictive Models for Dynamic Modulus of Hot-Mix Asphalt, Journal of Materials in Civil Engineering, ASCE, 21(6), (2009), 286-293, DOI 10.1061/(ASCE)0899-1561(2009)21:6(286)

8 Bayrak MB, Alper G, Halil C, Rapid pavement backcalculation technique for evaluating flexible pavement systems, Mid-Continent Transportation Re- search Symposium, In: Proceedings of the Mid-Continent Transportation Research Symposium; Ames, IA, USA, 2005.

9 Hashash YMA, Ghaboussi J, Fu Q, Marulanda C, Constitutive soil behavior representation via artificial neural networks: a shift from soil models to soil behavior data, GeoCongress 2006, In: Proceedings of GeoCongress, ASCE; Atlanta, GA, USA, 2006.

10 Kisgyorgy L, Rilett LR, Travel time prediction by advanced neural network, Periodica Polytechnica Civil Engineering, 46, (2002), 15-32.

11 Tarawneh B, Pipe pile setup: Database and prediction model using artificial neural network, Soils and Foundations, 53(4), (2013), 607-615, DOI 10.1016/j.sandf.2013.06.011

12 Tarawneh B, Imam R, Regression versus artificial neural networks: Predicting pile setup from empirical data, KSCE Journal of Civil Engineering, 18(4), (2014), 1018-1027, DOI 10.1007/s12205-014-0072-7

13 Mohammad LN, Gaspard K, Herath A, Nazzal M, Comparative evaluation of subgrade resilient modulus from non-destructive, in-situ, and laboratory methods, Louisiana Department of Transportation/FHWA, 2008. Final Report, Report No. 736-07-0406.

14 A2K05(3) Subcommittee on Neural Nets and Other Computational Intelligence-Based Modeling Systems, Use of artificial neural networks in geomechanical and pavement systems, TRB Circular, E-C012, (1999).

15 Rumelhart DE, Hinton GE, Williams RJ, Learning representations by back-propagating errors, Nature, 323(6088), (1986), 533-536, DOI 10.1038/323533a0

16 Al Tarawneh BK, Inspection, durability, and risk assessment of highway culverts, Ph.D. Thesis, Ohio University, 2005. 